\title{
Social Innovation and the Future of Business and Business Education
}

\author{
Michael Pirson $^{1} \cdot$ Lerzan Aksoy $^{1} \cdot$ Sertan Kabadayi $^{1}$
}

Published online: 7 January 2020

(C) Springer Nature Switzerland AG 2020

We are witnessing the fracturing of the traditional business system. Global governments demand business to not only focus on financial outcomes but rather advance progress towards the sustainable development goals. Customers of all ages but especially of the millenial and younger cohorts are pressuring companies towards more ethical business practices. Investors like Larry Fink demand long term oriented management. The business roundtable in the United States feels it needs to revoke the tenets of shareholder value maximization and reuissues their statement on the purpose of the corporation to be stakeholder value creation. While these trends are occuring at the surface level and many observers remain very cynical we argue that there is a deeper shift occuring.

Some observers call it a shift in consciousness and argue that we witness a new paradigm emerge. In the Fall of 2018 a number of thought and action leaders gathered in Tarrytown, NY at the invitation of the Gabelli School of Business to explore the deeper shifts occuring. The concept of social innovation provided the brackets and organizing focus of the conference. Five subcontexts were explored in separate tracks by teams of 5-6 participants.

The first track focused on the notion of dignity as an central concept to explain the paradigm shift occuring. Dignity is often used as a casual termwithstanding its potential power as a foundational organizing principle. Scholars have argued that dignity can be as foundational a concept as utility has been to think about organizing economic and political affairs. The track explored this proposition and discussed the notion of human dignity as cornerstone of innovative efforts. Dignity understood as that which is beyond price and intrinsically valuable challenges traditional and dominant theories of organizing, including innovation. Some of the questions this track explored were related to how we can manage to protect dignity and what kind of innovation processes do managers need to engage with to foster social innovation that honors, protects, promotes and restores dignity. Michael Pirson was joined by Erica Steckler of the University of Massachusetts, Bill English of Georgetown University, Canan Corus of Pace University, Andy Wicks of the University of Virginia and Mario Vazquez Maguirre of the Universidad de Monterrey for this track.

The second track focused on advancing our understanding of designing human-centered services to facilitate social innovation. Delivering services is an essential component of social innovation projects that bring positive societal change. This track, incorporated both Transformative Service

Michael Pirson

pirson@fordham.edu 
Research and Humanistic Management frameworks, and explored how services can be designed not only to improve individual and collective well-being but also to protect and promote human dignity to create solutions for societal problems. Sertan Kabadayi was joined by David Wasieleski of Duquesne University, Linda Nasr of Texas State University, Reut Livne-Tarandach of Manhattan College, Ann Marie Puente of Greyston's Center for Open Hiring and Garrett Broad of Fordham University.

The third track focused on how we think about creating systemic change to promote social innovation. Addressing solutions to complex problems requires a systems thinking approach in which the ecosystem, players within it, stakeholders, incentives and root causes to the problem are identified. This track explored issues surrounding how systemic change can be brought about effectively to solve societal challenges. Lead by Ray Fisk of Texas State University the team included Bjoern Mitzinnek of the University of Groningen, Chris Laszlo of Case Western Reserve University, Carey Weiss of Fordham University as well as leading social entrepreneur Patrick Struebi of Fairtrasa/Blooom and Fordham University Gabelli Fellow. They were joined by leaders of Ashoka, the organization credited with shaping the field of social entrepreneurship, Angie Fuessel of AshokaU and Alessandro Valera of Ashoka Italy.

The fourth track focused on measuring outcomes of social innovation efforts. For managers to embrace social innovation at scale, they must be able to identify what works and what doesn't both in terms of addressing the targeted sustainability issue and in its financial return to the firm. Moreover, socially conscious investors need this information to make better investment decisions. Ideally, sustainability initiatives will result in a virtuous cycle of higher levels of employee engagement and satisfaction, higher customer satisfaction loyalty, increased firm profitability and stock performance, in addition to achieving the socio-economic or environmental aims of the initiatives. This track explored the UN's sustainable development goals and other issues concerning performance and impact. Timothy Keiningham of St. John's University was joined by Charles M Clark of St. John's University, Anuar Juraidini of the Citi foundation, Mark Rosenbaum of the University of South Carolina, Alexander Buoye of Fordham University and Jay Kandampully of Ohio State University (Clark et al. 2019).

The fifth track focused on how business schools are currently approaching developing changemaking capabilities required by anyone intent to engage with social innovation and what needs to happen to transform future business education. Creating change that has a positive impact on the world requires individuals and teams engaged in the process to have certain capabilities, structures and processes. This includes knowing how to take others' perspective, ability to build consensus, overcoming obstacles, negotiation skills among others. This track focused on extensive data collection from more than 60 institutions worldwide and conducted in-depth interviews with 8 social intrapreneurs to identify 1) the current landscape and approaches to social innovation education, 2) skills developed successfully in future leaders, 3) gaps in skill development and existing structures and 4) a pathway forward for business education. Lerzan Aksoy of Fordham University was joined by Hooria Jazaieri of Northwestern University, Raj Sisodia, founder of Conscious Capitalism and Professor at Babson College, Jeffrey Nesteruk of Franklin and Marshall College, Yuliya Komarova of Fordham University and Katherine Milligan of Bamboo Capital Partners, Fordham University Gabelli Fellow and formerly from the Schwab Foundation at the World Economic Forum..

All tracks were linked to the underlying paradigm shift that is occurring. The track teams met for two days from November 1 to November 3, 2018. The teams were meeting and discussing the core of the paper and sketched out its main goals and contributions, an outline and a plan for completion. After the papers were complete they were reviewed and the editorial 
team asked for prominent thought leaders in the field to provide a response to the papers. We were able to receive responses to all papers in time for this special issue. Santiago Mejia of Fordham University, a business ethicist and philosopher responded to the paper provided by track 1. Ray Fisk of Texas State University responded to the paper provided by track 2 . Hunter Lovins, a prominent Sustainability scholar and teacher responded to the paper provided by track 3. Matthew Lee of Harvard University responded to the paper provided by track 4 and Jerry White, professor of Social Innovation Practice at University of Virginia, Fordham University Gabelli Fellow and a Peace Nobel Laureate responded to the paper provided by track 5.

In the first paper, Pirson et al. (2019) examine dignity and its role in the process of social innovation. The authors are particularly looking at lessons from the domains of Social Entrepreneurship and Transformative Services to highlight how the concept of dignity can help shape the process of social innovation. The growth of social entrepreneurship, social innovation, and transformative services highlights a shift away from conventional adherence to profit- and shareholder-driven business models. The fields of social entrepreneurship, social innovation, and transformative services have emerged as the dignity gap in economic organizing has gained attention. All these collective efforts are addressing the necessity for dignitybased products, services, and practices.

In their paper the authors advance an inquiry into human dignity in relation to the theory and practice of social entrepreneurship and innovation in a two-fold manner. First, they explore how concepts from the literatures of human dignity and humanistic management can inform and enrich social entrepreneurship and innovation. Second, they examine case studies of social entrepreneurship and innovation to refine how we think about and operationalize notions of human dignity. In this way, they connect human dignity research more closely to alternative life-conducive forms of organizing. The authors goals are to advance an understanding of human dignity and to make this concept more accessible and relevant in business and management, as well as to explore how the practice of social entrepreneurship and innovation can both enrich and be enriched by the notion of human dignity. Third, the authors draw on the emerging literature of humanistic management to generate a classification system in the context of social innovation that specifies how organizing can contribute to dignity restoration, dignity protection, and dignity promotion. They elaborate and showcase paradigmatic cases, probe the limits of these cases for future research, and consider how to extend this dignity organizing model to other modes of business practice, such as the notion of value creation. Finally, the authors outline an emerging research agenda for those interested in connecting innovation and organizing practices writ large with the notion of human dignity.

Mejia (2019) in his response discusses the nature of the moral imperatives that Humanistic Management seems to propose. In particular, he discusses whether Humanistic Management should be seen as an inspirational invitation to reimagine how organizations could be conceived and practiced or as a mode of organizing which is mean to replace our current forms of organizing and which we have a moral imperative to adopt. He argues that while dignity based organizing models are highly inspirational, he questions whether they can become a novel standard- a de facto requirement which replaces currently dominant forms of organizing.

In the second paper, Kabadayi et al. (2019) explore how humanistic management, social innovation and transformative service research overlap and inform each other. Humanistic Management and Transformative Service Research literatures share the common goal of addressing the increasingly growing global challenges faced by humanity. Recently, organizations have been called to further engage in social innovation in service (SIS) in an attempt to 
address these challenges. However, the existing service literature does not offer explicit processes regarding how to manage these social innovation efforts at the human interaction level. By drawing on both Humanistic Management and Service literatures, this paper develops a conceptual framework to guide the social innovation in service efforts. More specifically, this paper aims to answer a key question of: how can organizations manage human interactions to help maximize social innovation in service (SIS) outcomes? This paper identifies four foundational values (respect, trust, fairness, and inclusion) that should be at the core of the proposed processes (communication, collaboration, and compassion) needed in order to achieve the desired outcomes of SIS (relieving suffering, increasing well-being, and protecting and promoting human dignity). Subsequently, the authors offer a typology of service organizations with different combinations of processes at the human interaction level, highlighting the synergistic effect of the three identified processes. The proposed framework in this paper is a first step in bridging two disciplines to highlight their potential and role in addressing the global challenges.

Fisk (2019) commends the efforts by Kabadayi et al. and suggests that it is a very much needed first step. He argues that a conceptual paper such as this creates space for future researchers to collect and analyze secondary and primary data to dig deeper. The authors provide several interesting future service research directions involving various data sources from service organizations. He suggests one more future research topic that would expand beyond their conceptual foundation. Significant service research in Service-Dominant Logic (S-D Logic) (Vargo and Lusch 2004) has pushed service researchers beyond their foundations studying service interactions to investigating service systems and service ecosystems. Applying the conceptual framework of this article to service systems and service ecosystems would be highly desirable. In addition to humanistic service interactions, the world needs humanistic service systems and humanistic service ecosystems.

In the third paper, Fisk et al. (2019) look at the systemic implications of social innovation. The authors argue that society is at a crossroads. They argue that unprecedented rates of systemic social change are possible for co-creating a future where humans and all life can thrive. Yet, this requires innovation in the conceptions, practice, teaching, and researching of social innovation itself to reimagine what it is and can be. The authors integrate our perspectives on social innovation and humanistic management to suggest the notion of systemic social innovation. They introduce the concept of "transformative collaboration" as central to facilitating systemic social innovation and propose a multilevel model for accelerating systems change. The authors then develop an integrated framework for conceptualizing systemic social innovation. Four levels of social impact are identified, and these levels are bracketed with a call for transforming individual consciousness at the micro level and a new collective mindsets at the macro level. Blooom is presented as a case study to illustrate transformative collaboration, demonstrate the role of mindset shift in practice, and introduce four key ingredients to systemic social innovation. Finally, the authors issue a call to action for social innovation practice, teaching, and research. Most importantly, they seek to inspire and accelerate systemic social innovation that enables the flourishing of every human being and all life on earth.

Lovins (2019) finds much to agree and support, yet wishes for more specificity on who and in what areas people should be collaborating transformationally. Hunter Lovins suggests that similar perspectives on systems thinking had been provided by Buckminster Fuller. She also agrees that we have all the solutions we need to address the current problems. The possibilities of adding novel solutions is also on the horizon. She argues that to collaborate transformationally we need to make these mechanisms and processes accessible to all. In addition to 
Blooom she suggests that people interested in systemic transformation look at the Well Being Economy Alliance (WE All) and John Fullerton's regional hubs of regeneration. While there is much to be depressed about in this world, there are solutions emerging that can point to a finer future.

The fourth paper by Keiningham et al. (2019) examines several key factors believed to promote human flourishing, specifically: Factor 1: Age, Education, \& Healthcare, Factor 2: Labor Force Participation, Factor 3: Crime, Factor 4: Income, Factor 5: Youth Unemployment and Factor 6: Voting Behavior. The authors focus on existing data to measure flourishing. As a result, data was examined at the county level, and collected from a variety of US government and non-governmental organizations. The authors investigation into the conditions necessary to promote human flourishing uses internal migration within the United States (measured by moving to another county) as the indicator of "unhappy" communities. The findings reveal that all factors are important in emigration (i.e. leaving) somewhere, but the factors vary for different counties. As a result, attempts to address the ills of society require an appreciation of geography and context.

Matthew Lee, Director of Harvard University's Human Flourishing Program, agrees with the paper's pragmatic approach and premises (Lee 2019). He agrees that it is obviously important to understand these regional differences. But he asks a more fundamental question: what is flourishing? He acknowledges at the outset that the authors utilized existing data and that his suggestions for enriching the analysis of flourishing would require substantial new data collection. His comments are not necessarily a critique of the article. But as there are many different conceptions of "flourishing," each of these reflects distinct philosophical and theological presuppositions, that play into pragmatic measurement choices. Lee asks whether and despite a proliferation of measures of flourishing there are essential elements that might be universally valued across cultures.

He also points out the challenge that immediately arises with regard to determining when an activity is truly "life-conducive." He argues that many of the common markers of a flourishing life - hedonic happiness, financial success, material possessions - might be understood as reflecting "adaptive preferences" (Elster, 1983/2016). For example, people may desire a superficial, materialistic lifestyle because this is readily attainable in a consumeristic society, rather than the more difficult path of the virtuous life. He suggests that to get at the deeper levels of flourishing, we should integrate the wisdom of the humanities into social scientific research in order to achieve a right ordering of foundational and ultimate aspects of flourishing.

The fifth paper by Aksoy et al. (2019) focuses on the educational approaches to promote changemaking. The authors argue that business schools are uniquely positioned and have a responsibility to contribute to social innovation education. A landscape survey of social entrepreneurship / social innovation (SE/SI) education with 66 institutions of higher education and in-depth interviews with 8 social intrapreneurs from diverse career tracks reveals significant challenges as well as opportunities for creating this paradigm shift in business schools. The authors' research uses insights from these two studies to provide an overview of the current state of SE/SI in business education and provides recommendations for institutions of higher education to pave a pathway forward for future leaders who will use business to create positive social change.

Jerry White, a professor of practice at the University of Virginia, a Gabelli Fellow at Fordham University and a co-recipient of the Nobel Peace Prize, views the article positively and challenges all educators to shift more swiftly not only what we teach but how we teach (White 2019). He also argues that rather than invent separate programs of social innovation, 
integration is necessary. He further states that "it turns out, this century, we're all wet babies needing a change, whether we are nascent change-makers, change-leaders or change-managers. It's high time we boldly integrate innovation, social or otherwise, across the board, together, to match the needed cultural and structural shifts to serve aspiring business students and leaders going forward. [...] Social impact should be aligned in every single core business class. This would have the biggest impact." Yes, make it normal for business education, like brushing and flossing."

Finally, we include an essay by Katherine Milligan, Head of Gender and Diversity and Bamboo Capital Partners, Fordham University Gabelli Fellow and long time director of the Schwab Foundation for Social Entrepreneurship at the World Economic Forum (Milligan 2019). She questions the focus on heropreneurship in many social innovation oriented programs. She proposes ways to move towards empowering everyone to be a changemaker. If that occurs, indeed a paradigm shift is on its way.

The editorial team of the Special issue thanks everyone involved with this exciting project. We hope to spark more conversation and research on social innovation going forward.

\section{References}

Aksoy, L., H. Jazaieri, Y.K. Loureiro, K. Milligan, J. Nesteruk, R. Sisodia 2019. Transforming Business Education through Social Innovation: From Exalting Heroes to Engaging Our Humanity. Humanistic Management Journal, https://doi.org/10.1007/s41463-019-00068-4

Clark, C.M.A., A. Buoye, T. Keiningham, J. Kandampully, M. Rosenbaum, A. Juraidini 2019. Some Foundational Factors for Promoting Human Flourishing. Humanistic Management Journal, https:/doi. org/10.1007/s41463-019-00064-8

Elster, J. 2016. Sour grapes: Studies in the subversion of rationality. Cambridge: Cambridge University Press (Original work published 1983).

Fisk, R.P. 2019. Commentary on "Humanistic Management of Social Innovation in Service (SIS): An Interdisciplinary Framework". Humanistic Management Journal, https://doi.org/10.1007/s41463-01900070-w

Fisk, R., A. Fuessel, C. Laszlo, P. Struebi, A. Valera, C. Weiss 2019. Systemic Social Innovation: Co-Creating a Future Where Humans and all Life Thrive. Humanistic Management Journal, https://doi.org/10.1007 /s41463-019-00056-8

Kabadayi, S., L. Alkire, G.M. Broad, R. Livne-Tarandach, D. Wasieleski, A.M. Puente 2019. Humanistic Management of Social Innovation in Service (SIS): an Interdisciplinary Framework. Humanistic Management Journal, https://doi.org/10.1007/s41463-019-00063-9

Lee, M.T. 2019. Promoting Human Flourishing Beyond Foundational Concerns. Humanistic Management Journal, https://doi.org/10.1007/s41463-019-00065-7

Lovins, H. 2019. Commententary on "Systemic Social Innovation: Co-Creating a Future Where Humans and all Life Thrive". Humanistic Management Journal, https://doi.org/10.1007/s41463-019-00074-6

Mejia, S. 2019. The Moral Imperatives of Humanistic Management. Humanistic Management Journal, https://doi.org/10.1007/s41463-019-00069-3

Milligan, K. 2019. Essay: How Social Entrepreneurship and Social Innovation Can Transform Business Education. Humanistic Management Journal, https://doi.org/10.1007/s41463-019-00075-5

Pirson, M., M. Vázquez-Maguirre, C. Corus, E. Steckler, A. Wicks 2019. Dignity and the Process of Social Innovation: Lessons from Social Entrepreneurship and Transformative Services for Humanistic Management. Humanistic Management Journal, https://doi.org/10.1007/s41463-019-00071-9

Vargo, S.L., and R.F. Lusch. 2004. The four service marketing myths: remnants of a goods-based, manufacturing model. Journal of Service Research 6 (4): 324-335.

White, J. 2019. Transforming Purpose-Driven Business Education and Innovation [in a Complex World]. Humanistic Management Journal, https://doi.org/10.1007/s41463-019-00077-3 